\title{
Editorial: Enhancement of Ductility of FRP-Concrete Structures
}

\author{
Yingwu Zhou ${ }^{1 *}$, Zhenyu Huang ${ }^{1}$, Long-yuan $L^{2}{ }^{2}$ and Baolin Wan ${ }^{3}$ \\ ${ }^{1}$ Guangdong Province Key Laboratory of Durability for Marine Civil Engineering, School of Civil Engineering, Shenzhen University, \\ Shenzhen, China, ${ }^{2}$ School of Engineering, Computing and Mathematics, University of Plymouth, Plymouth, United Kingdom, \\ ${ }^{3}$ Department of Civil and Environmental Engineering, Marquette University, Milwaukee, WI, United States
}

Keywords: FRP, ductility, composite structures, strengthening, concrete structures

Editorial on the Research Topic

Enhancement of Ductility of FRP-Concrete Structures

Reinforced concrete has become the most widely used construction material in the world. Reinforced concrete combines the best features of concrete and reinforcement and it is a wonderful composite material. Owing to the corrosion of reinforcing steel, fiber reinforced polymers (FRPs) are considered to be a promising alternative to steel reinforcement, especially in concrete structures subjected to an aggressive environment or to the effects of electromagnetic fields. Although attempts to develop effective reinforcement have been followed, the application of FRPs remains limited; this is partly because the variation in the material properties of FRP composites and partly because there is limited knowledge gained by engineers as regards the application aspects of FRP composites and structural mechanics of concrete elements reinforced with FRPs. In order to promote research and applications of FRPs reinforced concrete in civil engineering, a special issue with the research topic of "Enhancement of Ductility of FRP-Concrete

Edited and reviewed by: John L. Provis, The University of Sheffield, United Kingdom

${ }^{*}$ Correspondence: Yingwu Zhou ywzhou@szu.edu.cn

Specialty section: This article was submitted to Structural Materials, a section of the journal

Frontiers in Materials

Received: 09 December 2020 Accepted: 22 December 2020 Published: 05 March 2021

Citation:

Zhou Y, Huang Z, Li L and Wan B (2021) Editorial: Enhancement of Ductility of FRP-Concrete Structures.

Front. Mater. 7:639538

doi: 10.3389/fmats.2020.639538 Structures" has been proposed and organized by the Guest Editorial team through the platform of Frontiers in Materials: Structural Materials. The main objectives of this Research Topic are to present recent research achievements in the studies and applications of FRPs reinforced concrete in civil engineering.

This special issue contains seven papers, three of which are related to the materials behaviors of FRPs reinforced concrete, two of which are associated with the structural behaviors of FRPs reinforced concrete structural members under impact loads, and the other two papers discussed the repair techniques. Among the seven papers, Zhang et al. reported their experimental study on the bond behavior of GFRP-reinforced ECC using pull-out tests, in which the bond-slip relationship and failure mechanism between GFRP reinforcing bars and ECC matrix were examined. $\mathrm{Hu}$ et al. proposed two techniques of shear strengthening using U-wrapped CFRP and effective anchoring devices. Test results were provided to demonstrate their performance in enhancing the shear strength and ductility of retrofitted RC beams. Yuan et al. investigated experimentally the flexural behavior of GFRP reinforced composite beams. Their experimental results showed that the flexural strength and stiffness of the RC beam members were significantly improved by using GFRP tubes. Ye et al. reported their experimental study on the performance of LRS-FRP strengthened RC beams under static and impact loads. The effects of FRP types, loading rate, and the use of end-anchorages on the strengthening efficiency were discussed. He et al. also conducted a study on the performance of RC beams with and without FRP reinforcement under impact loads by using both experimental and numerical methods. The results demonstrated that 
CFRP can significantly improve the resistance of beams to impact loading. Lv et al. carried out a study on the optimal mix design of calcium sulfoaluminate based ECC for rapid repairing of concrete members. Their work demonstrated that the calcium sulfoaluminate-ECC has excellent bonding strength to the concrete matrix. Li et al. presented an experimental study on the behavior of pre-damaged recycled aggregate concrete cylinders repaired with CFRP or large rupture strain FRP jackets. A total of 58 concrete cylinders with variations in the replacement ratio, damage level, and FRP property were tested. The test results demonstrated that the ultimate strain and strength of damaged recycled aggregate concrete could be significantly enhanced by FRP jackets and that aggregate quality plays a vital role in the strength of confined concrete. All of the above seven papers were written by experienced researchers who are actively working in the field of FRP reinforced concrete. The Guest Editorial team is confident that the work provided in the issue will be beneficial to the community of researchers, engineers, and other stakeholders who are interested in applying FRP reinforced concrete (RC) elements in civil engineering.

\section{AUTHOR CONTRIBUTIONS}

All authors listed have made a substantial, direct, and intellectual contribution to the work and approved it for publication.

Conflict of Interest: The authors declare that the research was conducted in the absence of any commercial or financial relationships that could be construed as a potential conflict of interest.

Copyright (c) 2021 Zhou, Huang, Li and Wan. This is an open-access article distributed under the terms of the Creative Commons Attribution License (CC $B Y)$. The use, distribution or reproduction in other forums is permitted, provided the original author(s) and the copyright owner(s) are credited and that the original publication in this journal is cited, in accordance with accepted academic practice. No use, distribution or reproduction is permitted which does not comply with these terms. 